\section{THE CANADIAN INSTITUTES OF HEALTH RESEARCH INSTITUTE OF INFECTION AND IMMUNITY RESPONSE TO THE THREAT OF ANTIMICROBIAL RESISTANCE}

The widespread use of antibiotic compounds promotes the emergence of resistant strains, resulting in a change in the proportion of microbes in a given setting and allowing resistant strains to become predominant over sensitive organisms. The recent increase in awareness of antimicrobial resistance (AMR) is due largely to the rise in nosocomial infections but also to the emergence of antibiotic resistance in community settings. This increase includes community-acquired methicillin-resistant Staphylococcus aureus and the recently discovered New Delhi metallo- $\beta$-lactamase 1. The problem of resistance is not limited to bacteria; many viruses, fungi, and parasites have developed resistance to prevalent therapies. Unless novel therapies are found to treat microbial infections, we may soon return to a preantibiotic state in which such infections were frequently lethal.

The Canadian Institutes of Health Research (CIHR), an agency of the government of Canada, is the major funder of health and health-related research in the country. The Institute of Infection and Immunity (III) is one of CIHR's 13 "virtual" institutes, which supports research and builds research capacity in the areas of infectious disease and the immune system, and which has spearheaded several strategic initiatives targeting AMR. These investments, along with funding through CIHR's open suite of programs, have led to the creation of knowledge and to knowledge translation, triggering a third-place ranking for Canada in relative citations in peer-reviewed publications in the field of AMR. Canada also ranks third for relative change in number of publications from 1997 to 2008, with a 4.9-fold increase for a total of 1258 publications (http://www.cihr-irsc.gc.ca/e/43717.html, figure 3), showing how critical this support has been to the growth of this community.

III launched a New Emerging Team grant in 2003, focused on antibiotic resistance in vulnerable populations. Two teams were funded for 5 years each, an investment of $\$ 2.5$ million. Several years later, III launched the Novel Alternatives to Antibiotics Initiative. Three priority themes-immune systems, phage therapy, and physical systems and biomaterialswere given precedence within the initiative. CIHR-III and its partners funded seed grants, fellowships, and emerging team grants for a total investment of more than $\$ 13$ million. Discoveries made through these programs have many practical possibilities, including the creation of safer microbial strains (1) and platforms to reduce the spread of germs in elementary schools (http://germsaway.ca).

CIHR often partners with other health organizations to launch wide-reaching funding opportunities. III spearheaded formation of the Canadian Research Coalition for Safe Food and Water in 2001, and in 2002 this coalition launched several initiatives. Seven teams were supported, and their researchers demonstrated the spread of antimicrobial-resistant organisms beyond health care settings (2). More recently, CIHRIII formed a significant partnership with the United Kingdom Medical Research Council and launched a team grant program in 2010 specifically targeting AMR. Two large teams, focusing on the interruption of bacterial cell wall biogenesis and $\beta$-lactam antibiotics, were funded through this partnership at a level of $\$ 4$ million each over 4 years.

CIHR is also addressing the threat of resistance to antivirals. The HIV/AIDS Research Initiative, at \$22.5 million per year, offers ongoing funding opportunities across the spectrum of HIV/AIDS research, including the field of resistance. Canadian scientists have identified the molecular mutations leading to reverse transcriptase inhibitor- and integrase inhibitor-resistant strains of HIV (3). In 2006, CIHR and its federal and provincial partners launched the Pandemic Preparedness Strategic Research Initiative (PPSRI) to address the threat of seasonal and pandemic influenza, which invested more than $\$ 45$ million over 5 years. More than 90 projects were funded through the PPSRI, and 12 of them focused on combating or characterizing neuraminidase-resistant influenza. Canadian researchers identified novel neuraminidase inhibitors that function in previously resistant viral strains (4) and have developed innovative vaccine strategies to increase prevention and lessen the need for antiviral therapy.

Another key priority of III is building capacity and supporting the next generation of researchers. Through the CIHR Strategic Training Initiative in Health Research program, which aims to attract bright, creative research talent to Canada, III has funded 21 training programs for a total investment of $\$ 9.4$ million. Two of these programs-the Training Program in Interdisciplinary Research in the field of AMR and the International Centre for Infectious Diseases Training Program-supported numerous trainees and were prolific in their knowledge translation activities.

AMR is a serious problem that is responsible for the hospitalization of an estimated 250000 Canadians every year, 8000 of whom die (5). It is also a severe economic drain when the total costs of hospitalization, treatment, lost wages, and quality of life are taken into account. CIHR-III is committed to improving the 
lives of Canadians and the global community by supporting groundbreaking research on AMR and, along with its partners, has made considerable investments in this area in the past decade. In the coming years, these investments will remain a key focus as III continues to encourage innovation, promote international collaborations, support training of the next generation of researchers, and address health emergencies through multitheme initiatives, while increasing the knowledge base of the general public on this critically important issue.

Jennifer F. Raven Marc Ouellette

Canadian Institutes of Health Research Institute of Infection and Immunity

Quebec, Canada

Correspondence: marc.ouellette@crchul.ulaval.ca

\section{REFERENCES}

1. Garneau JE, Dupuis ME, Villion M, Romero DA, Barrangou $\mathrm{R}$, Boyaval $\mathrm{P}$, et al. The CRISPR/Cas bacterial immune system cleaves bacteriophage and plasmid DNA. Nature. 2010; 468(7320):67-71.

2. Mataseje LF, Neumann N, Crago B, Baudry P, Zhanel GG, Louie $\mathrm{M}$, et al. Characterization of cefoxitin-resistant Escherichia coli isolates from recreational beaches and private drinking water in Canada between 2004 and 2006. Antimicrob Agents Chemother. 2009;53(7):3126-30.

3. Scarth BJ, White KL, Chen JM, Lansdon EB, Swaminathan S, Miller MD, et al. Mechanism of resistance to GS-9148 by the Q151L mutation in HIV-1 reverse transcriptase. Antimicrob Agents Chemother. 2011;55(6):2662-9.

4. Hashem AM, Flaman AS, Farnsworth A, Brown EG, Van Domselaar G, He R, et al. Aurintricarboxylic acid is a potent inhibitor of influenza A and B virus neuraminidases. PloS One. 2009;4(12):e8350.

5. Zoutman DE, Ford BD, Bryce E, Gourdeau M, Hébert G, Henderson $\mathrm{E}$, et al. The state of infection surveillance and control in Canadian acute care hospitals. Am J Infect Control. 2003;31(5):266-72; discussion 272-3. 